\title{
Development of a Novel Method for Assessing Balance: the Quantitative Posturography System
}

Jacinta Browne

Technological University Dublin, jacinta.browne@tudublin.ie

Neil O'Hare

St. James's Hospital, Dublin

Follow this and additional works at: https://arrow.tudublin.ie/meduart

Part of the Physics Commons

\section{Recommended Citation}

Browne, J., O'Hare, N.: Development of a Novel Method for Assessing Balance: the Quantitative Posturography System. Physiological Measurement, Vol. 21, no. 4, pp.515-524. 2000. doi:10.1088/ 0967-3334/21/4/309

This Article is brought to you for free and open access by the Medical Ultrasound at ARROW@TU Dublin. It has been accepted for inclusion in Articles by an authorized administrator of ARROW@TU Dublin. For more information, please contact arrow.admin@tudublin.ie, aisling.coyne@tudublin.ie,gerard.connolly@tudublin.ie.

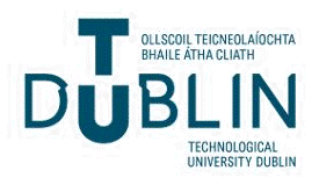




\title{
Development of a Quality Control Procedure for Force Platforms
}

Authors: Jacinta Browne and Neil O'Hare

Address: Medical Physics \& Bioengineering Department, St. James's Hospital, Dublin 8, Ireland.

\begin{abstract}
A force platform is a technical method of quantitatively assessing balance indirectly. The use of force platforms in physiotherapy departments has become more prominent over the last number of years. However, the main drawback in the use of force platforms is the lack of comprehensive calibration procedures, which casts doubt on the results obtained with these systems. Existing calibration tests are limited to testing the spatial accuracy of the force platform. This paper describes a comprehensive quality control test procedure, which was developed. It is proposed that the developed quality control test procedure could be used to test all types of force platforms and it includes: a description of how the tests should be carried out; the frequency with which they should be carried out and; the expected performance for each of the tests as recommended for the most part by the Association Francaise de Posturologie (Bizzo et al, 1985).
\end{abstract}

\subsection{Introduction}

Force platforms are technical methods of assessing balance and as such should have calibration results to verify the accuracy and precision of their clinical results. A significant deficiency in the use of force platforms is the lack of a comprehensive quality control test procedure which could be used to assess the accuracy and precision of the force platform measurements on a month-to-month or year-to-year basis (Andres and Anderson, 1980). The lack of such a quality control procedure casts doubt on the reliability of the various measured indices of balance described below, and also makes it impossible to compare results from month-to-month within the same clinic and between different clinics, even for the same type of force platform. It is very important to perform quality control tests so that it can be established if the performance of the force platform is within the specifications.

A force platform is an indirect technical method of measuring balance or sway, where the force exerted by the body on the ground is measured. From this measurement the person's centre of pressure (COP) is determined, and this is then related to their centre of gravity (COG) and ultimately to their balance. This is due to the relationship between these three parameters: the movement of a person's centre of gravity is a measure of their balance, and during quiet standing a persons centre of pressure can be approximated to their centre of gravity (Winter, 1995). Force platforms measure the COP using force or pressure transducers, which produce an electrical signal proportional to the applied force. There are many different types of force or pressure transducers in use: strain gauges, piezoelectric, piezoresistive and capacitive (Winter, 1990). A standard force platform is composed of a flat top plate supported by three or 
four force or pressure transducers. The location of a person's COP is determined by the relative forces experienced at each of these corner transducers. The following is a diagram of a standard force platform (Figure 1).

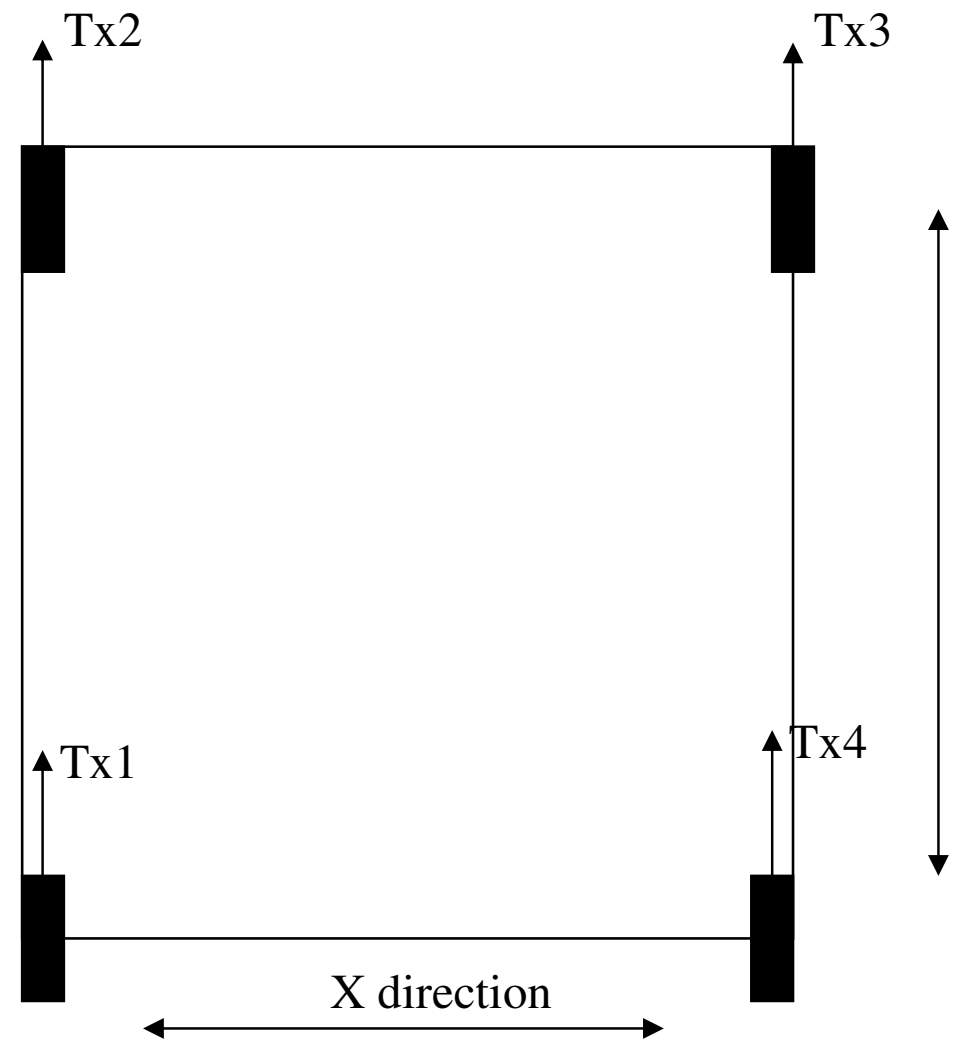

Y direction

Figure 1: Standard Force Platform

An analysis of the motion of the COP provides detailed quantitative measures of a person's postural stability, called indices of balance. Examples of some of these indices of balance are the following:

1. Average distance of the COP from the mean position [mm](Murray et al, 1975; Goldie et al, 1989; Kilburn et al, 1994),

2. The total excursion of the COP [mm](Kilburn et al, 1994; Fernie et al, 1978),

3. The mean instantaneous velocity of the COP [mm/sec](Kilburn et al, 1994; Fernie et al, 1978),

4. The mean frequency of the COP excursions [Hz](Hufschmidt et al, 1980;

Lakes et al, 1981; Geurts et al, 1993; Lucy et al, 1985),

5. Root mean square (r.m.s.) body sway velocity $[\mathrm{mm} / \mathrm{sec}]($ Uimonen et al, 1994),

6. The sway area which is the extent of the total area travelled by the COP in a given time. It has been found to be useful in quantifying the extent of visual 
influence on postural stability [ $\left.\mathrm{mm}^{2}\right]$ (Hufschmidt et al, 1980; Diener et al, 1984; Mc Clelland et al, 1989; Goldie et al, 1989; Jeong, 1994; Uimonen et al, 1994; Hasan et al, 1996(a)).

Balance disorders can result; from a loss of vestibular information, Mernier's Disease or vertigo; from damage to the CNS or the cerebellum, stroke or Parkinson's Disease; and also from damage to the musculoskeletal system. Different indices of balance are sensitive to the presence of different types of balance disorders (Geurts et al, 1993; Kilburn et al, 1994; Hufschmidt et al, 1980). The changes in the indices of balance due to impaired balance are not very large, $5 \mathrm{~mm}$ for healthy volunteer and $7.1 \mathrm{~mm}$ for a patient with moderate Parkinson's Disease a difference of only $2.1 \mathrm{~mm}$ (Browne, 1999). Therefore, the Force Platform measurements of the indices of balance need to be both accurate and precise.

Numerous investigators have carried out calibration tests on force platforms however, these calibration tests have been mostly limited to assessing only the spatial accuracy of the force platform and the sources of error causing the inaccuracy (Bobbert and Schamhardt, 1990; Mita et al, 1993; Granat et al, 1990; Hall et al, 1996; Starck et al, 1993). Each of the different investigators identified different sources of error for this spatial inaccuracy: excessive non-linearity of the transducer response; different offset voltages of each of the transducers; and electronic noise. Hall et al, 1996 suggested that a large source of error in the spatial accuracy of the force platform was due to the installation of the force platform and recommended that a calibration be performed at installation to minimise these errors. This calibration was limited to only determining the output and the crosstalk of each of the transducers. However, despite a knowledge of the errors which cause spatial inaccuracy no calibration procedure has been developed to include the testing of the different parameters which contribute to the errors in spatial accuracy; such as the level of non-linearity of the transducers or electronic noise in the analogue-to-digital converter signal of the force platform. Therefore, a quality control test procedure for characterising force platforms was developed. This quality control test procedure includes tests for all of the important aspects of the performance of force platforms, and the recommended performance criteria are for the most part those recommended by the Association Francaise de Posturologie to standardise the construction of force platforms (Bizzo et al, 1985). The Association Francaise de Posturologie recognised the need for standard construction specifications for force platforms to be developed and, therefore, outlined specifications for construction of a force platform with a spatial accuracy of $1 \mathrm{~mm}$ and a natural frequency greater than $20 \mathrm{~Hz}$. Despite it's obvious importance, no 
recommendation for precision was made by the Association Francaise de Posturologie and also, it has not been investigated by other investigators.

This quality control test procedure investigates the performance of force platforms from a static and a dynamic perspective. The static performance of the force platform is governed by its spatial accuracy and precision while the dynamic performance is governed by its frequency response. The spatial accuracy of the force platform is affected by the electronic noise and hysteresis of the system, the non-linearity and different offset voltages of the transducers as mentioned earlier. While the precision of force platform is affected by the repeatability and the temporal stability of the system. Therefore, in order for the static performance of the force platform to be fully investigated linearity, hysteresis, noise, repeatability and temporal stability will be investigated as well as spatial accuracy and uniformity. In order for the dynamic performance of the Force Platform to be investigated the natural frequency and the frequency response, Modulated Transfer Function (MTF) will be investigated. In this paper the quality control procedure for all types of force platforms is proposed.

\subsection{Methods}

\subsection{Quality Control Test Procedure}

This quality control procedure includes quality control tests which may be carried out on force platforms which either have access only to the COP measurements or have access to both the COP measurements and to the voltage output from the analogue to digital converter for each of the transducers. The part of the quality control procedure which uses the COP measurements will only provide general information about the force platform's accuracy and precision and will only allow problems with nonlinearity, hysteresis, noise, repeatability and stability of the force platform to be identified. Whereas, the part of the quality control procedure which uses the output voltage from the analogue to digital converter can pinpoint which transducer has excessive non-linearity, hysteresis, non-repeatability and instability.

All measurements should be made at room temperature $\left(22^{\circ} \mathrm{C}\right)$ and the temperature recorded at 30minute intervals while the QC procedure is being carried out. 


\subsubsection{Static Tests of the Quality Control Procedure}

\section{Spatial Accuracy}

Spatial accuracy is one of the most important parameters of a force platforms characteristics as it is essential for a patient's treatment management that small changes over time can be accurately detected (Berg, 1989). Spatial accuracy is affected by: non-linearity of the transducers response to applied load; hysteresis in the transducers; different offset voltages of the individual transducers and electronic noise in the individual components of the force platform. For example if the transducers have a non-linear response to applied load, then the COP may be underestimated or overestimated. The point of force application is measured using the force platform's own processing and analysis program therefore; the same test is used regardless of whether or not the output voltage from the analogue to digital converter is accessible. This is one of the more difficult tests to perform, in the QC procedure because of the difficulty with positioning the calibrated loads on the top plate of the system. If an accurate co-ordinate grid is placed on the top plate of the force platform, it will facilitate more accurate positioning of the loads on the top plate.

A number of different measurement techniques have been developed.

The spatial accuracy was measured by Barrett et al, 1987 and Mita et al, 1993 by placing different magnitudes of calibrated loads on the co-ordinate of interest. The loads were then removed and reapplied on the next co-ordinate of interest. This was repeated for up to 40 co-ordinates, which gave an adequate representation of the coordinates of the top plate for the range of loads between $7 \mathrm{~kg}-30 \mathrm{~kg}$. However, this method is time consuming and subject to large sources of inaccuracies in stacking the loads.

The spatial accuracy was measured by Starck et al, 1993; Bobbert and Schamhardt, 1990; Hall et al, 1996; and Gill and O'Connor, 1997 using dedicated rigs for applying loads of different magnitudes to specific locations, which gave an adequate representation of the co-ordinates of the top plate. A description of the construction of one such rig is described by Gill and O'Connor, 1997.

In this investigation a Translational Movement System was constructed, which translated a range of calibrated loads between $10 \mathrm{~kg}$ to $80 \mathrm{~kg}$ across the top plate of the force platform, without having to keep removing and reapplying the loads (Figure 3 ). The accuracy of the Force Platform is determined in a relative manner by the Translational Movement System, the loads are moved by $2 \mathrm{~cm}$ and the accuracy with 
which the Force Platform can measure this $2 \mathrm{~cm}$ change in position is determined. The Translational Movement System consisted of a moveable plate on which loads were stacked and then easily and accurately moved by $2 \mathrm{~cm}$ (an accuracy of $\pm 1 \mathrm{~mm}$ ). The loads were applied to 40 different locations, which gave an adequate representation of the co-ordinate of the top plate. The co-ordinate points measured were those contained within the area $\pm 10 \mathrm{~cm}$ from the origin in both the $\mathrm{x}$ - and $\mathrm{y}$-direction (Bizzo et al, 1985).

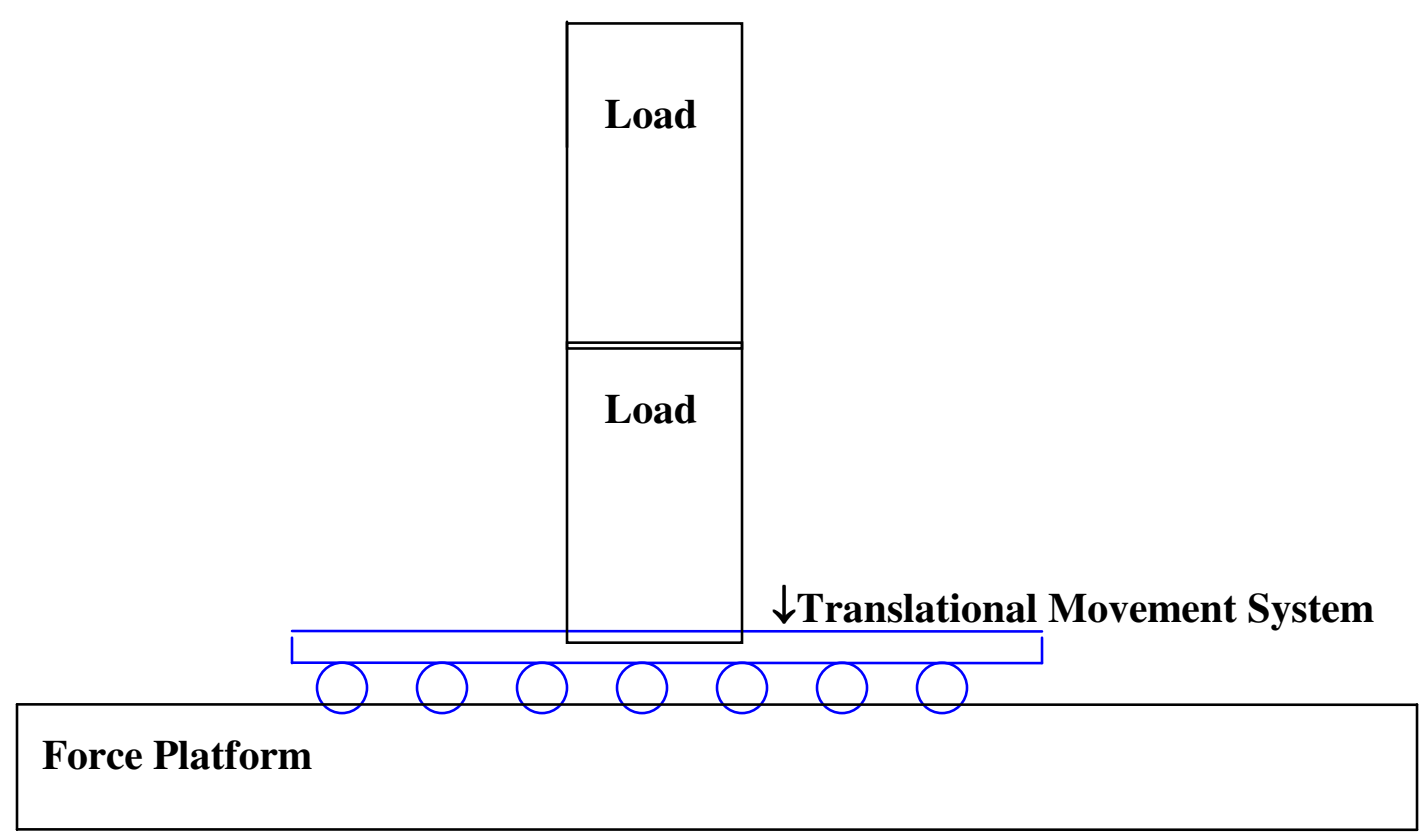

Figure 2 : Translational Movement System

The accuracy of the COP measurements should be accurate to within $1 \mathrm{~mm}$ when a $10 \mathrm{~kg}$ load is placed $10 \mathrm{~cm}$ out from the mechanical centre of the force platform (Bizzo et al, 1985; Barrett et al, 1987; Mita et al,, 1993; Starck et al, 1993; Gill et al, 1997).

This test should be carried out as part of acceptance testing and at a minimum of six monthly intervals thereafter unless the stability of the system is such that it needs to be carried out more frequently.

\section{Uniformity}

Uniformity is also an important parameter of the force platforms characteristics. If the force platform's top plate has a non-uniform response, then the measurements of a patient's COP will be affected if the patient stands on different positions of the top 
plate or if the area of their COP increases it will not be measured accurately.

Uniformity is affected by: non-linearity of the transducers response to load; hysteresis; different offset voltages of the individual transducers; electronic noise in the individual components of the force platform; and deformation of the top plate. The uniformity of the force platform's top plate is measured using the force platform's own processing and analysis program. The uniformity of the force platform top plate can be determined by applying a calibrated load between $10 \mathrm{~kg}-40 \mathrm{~kg}$ at a sufficiently representative number of co-ordinate points on the top plate. The co-ordinate points should be contained within the area $\pm 10 \mathrm{~cm}$ from the origin in both the $\mathrm{x}$ - and $\mathrm{y}$ direction (Bizzo et al, 1985). It is imperative that the load is accurately placed at each of the co-ordinates of interest and this can be achieved by placing a mat with the traced circumference of the base of the load on it and then positioning the load within the trace (Figure 4).

Figure 3: Top Plate of QPS with a Positioning Mat

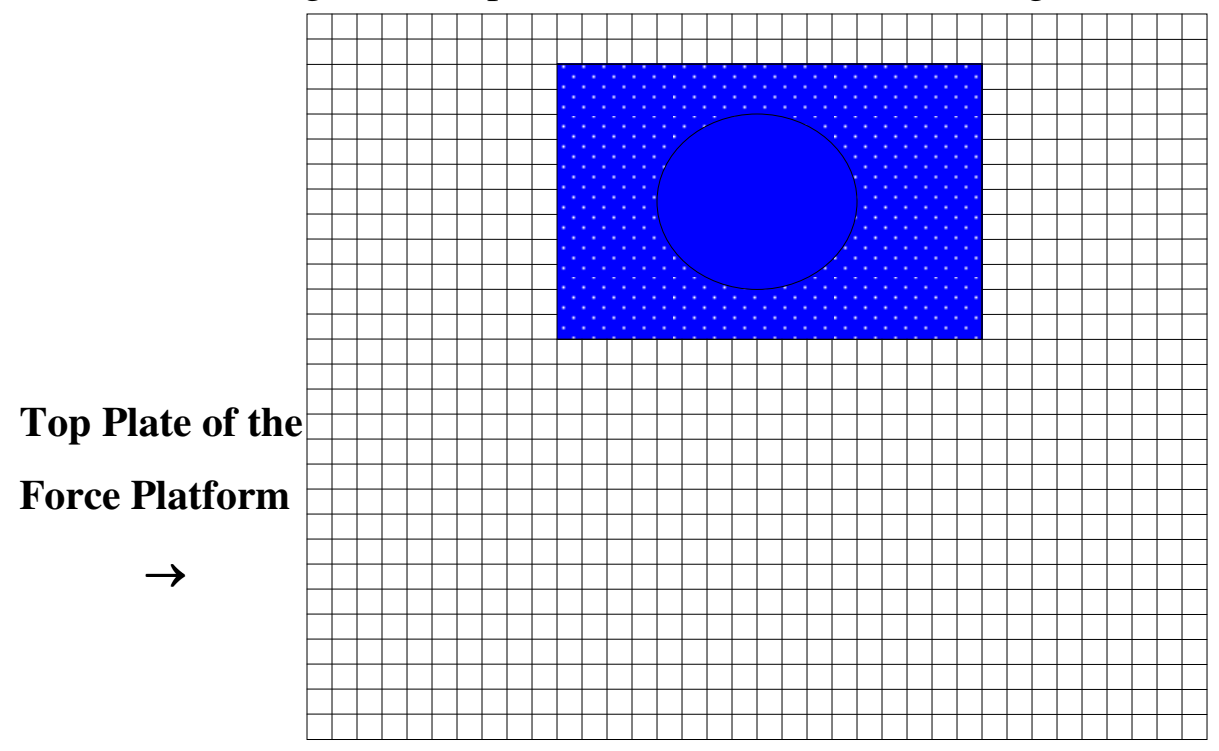

The force platform's top plate should have a uniform response to within $1 \mathrm{~mm}$ across the area contained within $\pm 10 \mathrm{~cm}$ from the mechanical centre in both the $\mathrm{x}$ - and $\mathrm{y}$ directions (Bizzo et al, 1985).

This test should be carried out as part of acceptance testing and at a minimum of monthly intervals thereafter unless the stability of the system is such that it needs to be carried out more frequently. It is also necessary to carry out a smaller daily check on the uniformity of the force platform, in which a calibrated load between $10 \mathrm{~kg}$ - 40kg on at least five random co-ordinates which adequately represent the top plate of the 
force platform. The co-ordinate points should be contained within the area $\pm 10 \mathrm{~cm}$ from the mechanical centre in both the $\mathrm{x}$ - and y-direction (Bizzo et al, 1985).

\section{Linearity}

In normal operation the range of applied loads for subjects is between $40 \mathrm{~kg}$ to $160 \mathrm{~kg}$ and each of the transducers will have this range of loads applied to them divided by the number of transducers in the force platform. Therefore, the linearity of the force platform's transducers should be determined for this range of loads.

The linearity of the force platform can be determined by applying calibrated loads of between $5 \mathrm{~kg}-100 \mathrm{~kg}$ to different positions on the top plate of the force platform and recording the COP measurements calculated. The COP measurements should not vary by more than $1 \mathrm{~mm}$. Therefore, the response of the COP measurements should be independent of the load applied (Bizzo et al, 1985).

Additional information about the linearity of the individual transducers can be obtained if the output voltage from the analogue to digital converter (ADC) is accessible. The linearity of the transducers can be determined by applying calibrated loads of between $5 \mathrm{~kg}-100 \mathrm{~kg}$ directly over each of the transducers and the output voltage response of each of the transducers recorded for the increasing magnitude of load. The offset voltage of each of the transducers can also be obtained. The offset voltages of each of the transducers should be the same for all of them otherwise the COP measurements will be inaccurate (Beppu et al, 1985; Mita et al, 1993). The transducers should have a non-linearity $<0.1 \%$ full scale (Bizzo et al, 1985).

This test should be performed as part of acceptance testing and at a minimum of yearly intervals thereafter unless the stability of the system is such that it needs to be carried out more frequently.

\section{Hysteresis}

In normal operation the loads applied to each of the transducers will increase and decrease within a few milliseconds as the subject sways to and from the transducers.

In order to simulate the clinical test situation a calibrated load between $20 \mathrm{~kg}-40 \mathrm{~kg}$ should be applied to different positions on the top plate of the force platform contained within the area $\pm 10 \mathrm{~cm}$ from the origin in both the $\mathrm{x}$ - and $\mathrm{y}$-direction and the COP measurements recorded. Then a smaller calibrated load between $5 \mathrm{~kg}-10 \mathrm{~kg}$ 
should be applied on top of the larger load and again the COP measurement recorded. The smaller load should then be removed and the COP measurement for the original calibrated load recorded. This test should be repeated at least four times at different positions contained within the area $\pm 10 \mathrm{~cm}$ from the origin in both the $\mathrm{x}$ - and $\mathrm{y}$ direction for an accurate measurement of hysteresis present in the system to be determined. The COP measurements should not vary by more than $1 \mathrm{~mm}$ (Bizzo et al, 1985).

Additional information about the hysteresis of the individual transducers can be obtained if the output voltage from the ADC is accessible. The level of hysteresis in each of the transducers can be determined by applying a calibrated load between $10 \mathrm{~kg}$ - 40kg directly over each of the transducers individually and the output voltage response of each of the transducers recorded once the output voltage becomes stable. Then a smaller additional calibrated load between $5 \mathrm{~kg}$ - 10kg should be applied on top of the larger load and again the output voltage of each of the transducers recorded once the output voltage becomes stable. The smaller load should then be removed and the output voltage response of the transducers for the original calibrated load recorded again once the output voltage becomes stable. The above procedure should be repeated at least four times so that the amount of hysteresis present in the transducers can be determined. The transducers should have hysteresis $<0.2 \%$ full scale (Bizzo et al, 1985).

This test should be performed as part of acceptance testing and at a minimum of yearly intervals thereafter unless the stability of the system is such that it needs to be carried out more frequently.

\section{$\underline{\text { Noise }}$}

The noise present in the force platform's measurements can be determined by applying a calibrated load between $10 \mathrm{~kg}$ - $40 \mathrm{~kg}$ to the force platform and the calculated displacement of the COP of the static calibrated load is representative of the amount of noise present in the system. The displacement of the COP measurement should be $<1 \mathrm{~mm}$ (Bizzo et al, 1985).

Additional information about the contribution of the transducers and the ADC can be obtained in the output voltages from the ADC is accessible. The noise in the force platform's measurements can be determined by applying a calibrated load between $10 \mathrm{~kg}-40 \mathrm{~kg}$ directly over each of the transducers and measuring the amount of variance in the output voltage signal of the analogue to digital converter, which 
corresponds to the noise in the signal. The noise level should contribute to $<1 \mathrm{~mm}$ inaccuracy in the spatial accuracy of the force platform COP measurements (Bizzo et al, 1985; Granat et al, 1990).

This test should be performed as part of acceptance testing and at a minimum of six monthly intervals thereafter unless the stability of the system is such that it needs to be carried out more frequently.

\section{$\underline{\text { Repeatability }}$}

Repeatability contributes to the precision of the COP measurements, it is important that the COP measurements are precise so that changes over time in the COP measurements can be detected. The repeatability of the force platform can be determined by applying a calibrated load of between $10 \mathrm{~kg}-40 \mathrm{~kg}$ to the force platform at least twenty times in the same position and recording the COP measurement obtained each time. It is important that the load is accurately placed in the same position each time, this can be achieved by using a placement mat described in the uniformity test procedure.

Additional information about the repeatability of the individual transducers can be obtained if the output voltage from the ADC is accessible. The repeatability of the transducers can be determined by applying a calibrated load between $10 \mathrm{~kg}-40 \mathrm{~kg}$ directly over each of transducers individually at least twenty times and measuring the output voltage response of the transducers from the analogue to digital converter. It is important that the load is accurately placed in the same position each time, this can be achieved by using a placement mat described in the uniformity test procedure.

The Association de Francaise made no recommendations for the repeatability of COP measurements, however upon consideration of the small magnitude of difference, $2 \mathrm{~mm}$, between patients with Parkinson's disease and age-matched healthy subjects it is evident that COP measurements should also be precise to within $1 \mathrm{~mm}$, in order to detect changes in subjects ability to balance (Browne, 1999; Berg, 1989; Hufschmidt et al, 1980).

This test should be carried out as part of acceptance testing and at a minimum of weekly intervals thereafter unless the stability of the system is such that it needs to be carried out more frequently. 


\section{Temporal Stability}

Drift and temporal stability also contribute to the precision of the COP measurements. The drift in the Force Platform measurements over a 5- 30 minutes time interval can be measured by placing a calibrated load between $10 \mathrm{~kg}-40 \mathrm{~kg}$ on the top plate and recording the COP measurements every 5 minutes.

Additional information about the drift in the individual transducers can be obtained if the output voltage from the ADC is accessible. The drift in the transducers over a 530 minutes time interval can be measured by placing a calibrated load between 10kg $40 \mathrm{~kg}$ over each of the transducers and recording the output voltage response of the transducers from the analogue to digital converter every 5 minutes.

The stability of the force platform over time can be determined by applying a calibrated load between $10 \mathrm{~kg}$ - 40kg to the force platform and recording the COP measurement obtained each time. It is important that the load is accurately placed in the same position each time, this can be achieved by using a placement mat described in the uniformity test procedure.

Additional information about the stability of the individual transducers can be obtained if the output voltage from the ADC is accessible. The stability over time of the transducers can be determined by applying a calibrated load between $10 \mathrm{~kg}-40 \mathrm{~kg}$ directly over each of the transducers and measuring the output voltage response of the transducers from the analogue to digital converter. It is important that the load is accurately placed in the same position each time, this can be achieved by using a placement mat described in the uniformity test procedure.

The Association de Francaise made no recommendations for the temporal stability of COP measurements, however upon consideration of the small magnitude of difference, $2 \mathrm{~mm}$, between patients with Parkinson's disease and age-matched healthy subjects it is evident that COP measurements should also be precise to within $1 \mathrm{~mm}$, in order to detect changes in subjects ability to balance (Browne, 1999; Berg, 1989; Hufschmidt et al, 1980).

This test should be carried out at a minimum of monthly intervals unless the stability of the system is such that it needs to be carried out more frequently. 


\subsubsection{Dynamic Test of the Quality Control Procedure}

\section{Frequency Response}

The frequency response of a force platform can be determined by using a rocking device such as a pendulum, which would simulate the sway of a subject and measuring the frequency and amplitude of the rocking device, using the force platforms own processing and analysis program. The rocking device frequency and amplitude would need to be controllable and be able to simulate a range of frequencies from $0 \mathrm{~Hz}-20 \mathrm{~Hz}$. Therefore, it could be evaluated whether the force platform reproduces all the input frequencies and at the correct amplitude.

Additional information about the force platforms frequency response can be obtained if the output voltage from the ADC is accessible. The frequency response of the force platform can be determined by applying an impulse to the force platform (Bizzo et al, 1985; Starck et al, 1993; Hall et al, 1996). An impulse can be applied by dropping a calibrated load between $5 \mathrm{~kg}-10 \mathrm{~kg}$ onto the top plate of the force platform. Once an impulse has been applied to the force platform the Point Spread Function (PSF) of the system can be measured from the output voltage of the analogue to digital converter. The Fast Fourier Transform of the PSF can then be calculated and from this the Modulation Transfer Function for the system can be determined. The natural frequency of the system can be determined from either the time domain plot of the point spread function or from the frequency domain plot of the point spread function. The modulation transfer function will indicate how the system represents the frequency components of sway.

The range of frequency components in sway is between $0 \mathrm{~Hz}-10 \mathrm{~Hz}$ therefore the recommended frequency of force platforms is that the natural frequency of the force platform should not be lower than $20 \mathrm{~Hz}$ (Bizzo et al, 1985). If the force platform has frequency components lower than $20 \mathrm{~Hz}$ then the amplitude of the subject's frequency components of their sway may be increased or decreased.

This test should be carried at acceptance testing and at a minimum of yearly intervals thereafter unless the stability of the system is such that it needs to be carried out more frequently. 
Table 1: Summary of the Quality Control Protocol

\begin{tabular}{|c|c|c|}
\hline Test & Expected Results & $\begin{array}{c}\text { Frequency Test } \\
\text { carried out }\end{array}$ \\
\hline Linearity & $\begin{array}{c}<0.1 \% \text { full scale } * \\
<1 \mathrm{~mm} *\end{array}$ & Installation \& yearly $* *$ \\
\hline Hysteresis & $\begin{array}{c}<0.2 \% \text { full scale } * \\
<1 \mathrm{~mm} *\end{array}$ & Installation \& yearly $* *$ \\
\hline Noise & $<1 \mathrm{~mm} * *$ & $\begin{array}{l}\text { Installation \& six monthly } \\
\qquad * *\end{array}$ \\
\hline Repeatability & $<1 \mathrm{~mm} * *$ & Installation \& weekly ** \\
\hline System Drift & $\begin{array}{c}<1 \mathrm{~mm} \text { over a } 30 \text { minute time } \\
\text { interval } * *\end{array}$ & Daily ** \\
\hline Temporal stability & $<1 \mathrm{~mm}$ over 1 year $* *$ & Monthly ** \\
\hline Spatial Accuracy & within $1 \mathrm{~mm} *$ & $\begin{array}{l}\text { Installation \& six monthly } \\
\qquad *\end{array}$ \\
\hline Uniformity & within $1 \mathrm{~mm} *$ & Installation \& monthly $* *$ \\
\hline $\begin{array}{l}\text { Spot check on } \\
\text { Uniformity }\end{array}$ & within $1 \mathrm{~mm} *$ & Daily ** \\
\hline Frequency Response & $\begin{array}{c}\text { No resonant frequencies } \\
\text { components below } 20 \mathrm{~Hz} *\end{array}$ & Installation \& yearly $* *$ \\
\hline
\end{tabular}

* As recommended by the Association de Francaise (Bizzo et al, 1985)

** Recommended from experimental evidence of the stability of a prototype Force Platform evaluated over a year (Browne, 1999) 


\subsection{Discussion}

A quality control procedure has been described which enables users to determine whether a force platform is performing to the required specifications, as provided by the Association Francaise de Posturologie (Bizzo et al, 1985). This paper is the first paper, to the authors knowledge, which outlines a comprehensive quality control procedure for Force Platforms and which recommends appropriate time intervals for carrying out each of the tests in the quality control procedure. However, the time interval suggested are only guidelines established after a year of testing a prototype Force Platform and therefore, further work needs to be carried out in order to establish a baseline of time intervals for Force Platforms of varying ages and varying complexity.

From the results of the quality control procedure sources of error caused by the electronic components of the Force Platform can be identified and if the output voltage from the ADC is accessible then the exact source of the error can be identified for example: excessive non-linearity of the transducer response, different offset voltages of the transducers or noise due to the ADC or mains. Corrections can be applied to correct for excessive non-linearity and different offset voltages in the transducers. Noise due to the ADC can be reduced by using a higher sampling frequency and then using a low pass filter, while noise from the mains can be reduced with better insulating shielding on the Force Platform wiring.

\subsection{Conclusions}

In this paper a quality control test procedure is outlined to allow the performance of force platforms to be evaluated and monitored over time. This quality control test procedure includes details of: what quality control tests should be carried out; how the quality control tests may be carried out; the frequency with which they should be carried out; and the typical performance required in order for the force platforms measurements to be regarded as accurate, precise and giving a faithful reproduction of the frequency components of the subject's sway. Without these quality control tests being carried out it is difficult for investigators to trust the results obtained and to compare results obtained for a patient undergoing physiotherapy as, the results obtained may not be accurate or precise. Table 1 is a summary of the quality control protocol. 


\section{References}

(Andres and Anderson, 1980)R. Andres, D. Anderson, 'Designing a Better Postural Measurement System', American Journal of Otolaryngology, 1, pp 197 - 206, 1980.

(Barrett et al, 1987)

R. Barrett, S.A. Hyde, W.B. Hark, 'The Design of a Force Platform for Clinical Use: A Feasibility Study of Stabilography in Evaluating the Effect of Orthotic Intervention in Duchenne Muscular Dystrophy', Journal of Med. Eng. And Tech., 11, pp 68 - 73, 1987.

(Beppu et al, 1985) M. Beppu, Y. Ehara, S. Monura, M Ikeda and S. Takahashi, 'Calibration of Force Plate with the Method of Least Squares', Bull. Kanagawa Prefectural Rehabil. Center, 10, pp 37 - 46, 1985.

(Berg, 1989)

K. Berg, 1989, 'Balance and its Measure in the Elderly: A Review', Physiotherapy Canada, 41, pp 240-245.

(Bizzo et al, 1985)

G. Bizzo, N. Guillet, A. Patat, P.M. Gagey, 'Specifications for Building a Vertical Force Platform Designed for Clinical Stabilometry', Med. \& Biol. Eng. \& Comput., 23, pp 474 - 476, 1985.

(Bobbert and Schamhardt, 1990)M.F. Bobbert and H.C. Schamhardt, 'Accuracy of Determining the Point of Force Application with Piezoelectric Force Plates', Journal of Biomechanics, 23, pp 705 - 710, 1990.

(Browne, 1999)

J. Browne, 'The Development of a Quantitative Posturography System and its Clinical Evaluation', M.Sc. Thesis, Trinity College Dublin, 1999.

(Diener et al, 1984)

H.C. Diener, J. Dichgans, M. Bacher, B. Gompf, 'Quantification of Postural Sway in Normals and Patients with Cerebellar Diseases', Electroencephalography and Clinical Neurophysiology, 57, pp 134 - 142, 1984.

(Fernie et al, 1978) G.R. Fernie, P.J. Holliday, 'Postural Sway in Amputees and Normal Subjects', The Journal of Bone and Joint Surgery, 60 - A, pp 895 - 898, 1978. 
(Geurts et al, 1993) A.C.H. Geurts, B. Nienhuis, T.W. Mulder, 'Intrasubject Variability of Selected Force - Platform parameters in the Quantification of Postural Control', Arch Phys Med Rehabil, 74, pp 1144 - 1150, 1993.

(Gill and O'Connor, 1997)H.S. Gill and J.J. O'Connor, 'A New Testing Rig for Force Platform Calibration and Accuracy Testing', Gait \& Posture, 5, pp 228 - 232, 1997.

(Goldie et al, 1989) P.A. Goldie, T.M. Bach, D.M. Evans, 'Force Platform Measures for Evaluating Postural Control: Reliability and Validity', Arch Phys Med Rehab, 70, pp $510-517,1989$.

(Granat et al, 1990) M.H. Granat, C.A. Kirkwood, B.J. Andrews, 'Problem with the Use of Total Distance Travelled and Average Speed as Measures of Postural Stability', Med. \& Biol. Eng. \& Comput, 28, pp 601 - 602, 1990.

(Hall et al, 1996) M.G. Hall, H.E. Fleming, M.J. Dolan, S.F.D. Millbank, J.P. Paul, 'Static in Situ Calibration of Force Plates', Journal of Biomechanics, 29, pp 659 - 665, 1996.

(Hasan et al, 1996) S.S. Hasan, D.W. Robin, D.S. Zurkus, D.H. Ashmead, S.W. Peterson, R.G. Shiavi, 'Simultaneous Measurement of Body Centre of Pressure and Centre of Gravity during Upright Stance: Part 1: Methods', Gait \& Posture, 4, pp 1 $10,1996$.

(Hufschmidt et al, 1980)A. Hufschmidt, J. Dichgans, K.H. Mauritz, M. Hufschmidt, ' Some Methods and Parameters of Body Sway Quantification and their Neurological Applications', Arch Psychiat Nervenkr, 228, pp 135 - 150, 1980.

(Jeong, 1994) B.Y. Jeong, 'Contour Representation of Sway Area in Posturography and its Application', Arch Phys Med Rehabil, 75, pp 951- 955, 1994.

(Kilburn et al, 1994) K.H. Kilburn, R.H. Warshaw, B. Hanson, 'Balance Measured by Head and a Force Platform in Chemically Exposed and Referent Subjects', Occupational and Environmental Medicine, 51, pp 381 - 385, 1994.

(Lakes et al, 1981)

R.S. Lakes, K. Korttila, D. Eltoft, A. Derose, M. Ghoneim, 'Instrumented Force Platform for Postural Sway Studies', IEEE Transactions on Biomechanical Engineering, BME - 28, pp 725 - 729, 1981. 
(Lucy et al, 1985)Postural Sway Profiles: Normal Subjects and Subjects with Cerebellar Ataxia', Physiotherapy Canada, 37, pp 140 - 148, 1985.

(Mclelland, 1989) G.R. $\mathrm{M}^{\mathrm{c}}$ Clelland, 'Body Sway and the Effects of Psychoactive Drugs - A Review', Human Psychopharmacology, 4, pp 3 - 14, 1989.

(Mita et al, 1993) K. Mita, K.A. Kataki, K. Itoh, H. Nogami, 'An Investigation of the Accuracy in Measuring the Body Centre of Pressure in a Standing Posture with a Force Plate', Frontiers of Medical Biological Engineering, 5, pp 201 - 213, 1993.

(Murray et al, 1975) M. Murray, A.A. Seireg, S.B. Sepic, 'Normal Postural Stability and Steadiness: Quantitative Assessment', The Journal of Bone and Joint Surgery, 57-A, pp 510 - 516, 1975.

(Starck et al, 1993) J. Starck, I. Pyykko, H. Aalto, J. Pekkarinen, ' Measurements of Postural Stability: Development of a Force Platform and Some Excitation Systems', Medical Progress Through Technology, 18, pp 209 - 215, 1993.

(Uimonen et al, 1994)S. Uimonen, K. Laitakari, R. Bloigu, M. Reinila, M. Sorri, 'Static Posturography and Intravenous Alcohol', Journal of Vestibular Research, 4, pp 277 - 283, 1994.

(Winter, 1990) D.A. Winter, 'Biomechanics and Motor Control of Human Movement', Wiley Interscience Publication, 2nd Edition 1990.

(Winter, 1995) D.A. Winter, 'Human Balance and Posture Control during Standing and Walking', Gait \& Posture, 3, pp 193 - 214, 1995. 